\title{
Class and gender in the hegemonic process: class differences in women's perceptions of television realism and identification with television characters
}

\author{
Andrea Press \\ DEPARTMENT OF COMMUNICATION, UNIVERSITY OF MICHIGAN, \\ ANN ARBOR
}

In this paper I compare the ways in which American working-class women receive television entertainment programming differently than do middle-class women. Specifically, I compare the type of identification with television characters made by each group, and differences between the way in which members of each group judge television content to be 'realistic'. I demonstrate that while many of our society's hegemonic values are present in television programming, they reach women of different social classes in class-specific ways. Working-class women are more likely to notice the middle-class material world which television depicts, and to judge this world to be representative of the real world. Middleclass women, in contrast, are more likely to identify personally with television characters and their problems, particularly those related to the family and situated in a family context.

As scholars theorizing the relationship between gender and class might predict, I conclude that the hegemonic process operates quite differently for working-class as opposed to middle-class women. While working-class women are much more susceptible to the class-specific features of the liberal, middle-class ideology characterizing the television entertainment medium, middle-class

Media, Culture and Society (SAGE, London, Newbury Park and New Delhi), Vol. 11 (1989), 229-251 
women are more responsive to its gender-specific features. As working-class women are lulled into accepting that their wishes regarding material reality constitute that reality itself, middle-class women are similarly encouraged by television's portrayal of the family to accept the interpersonal and familial ideals and goals which television presents, and to evaluate both their own lives and the behavior of television characters in light of these overall hegemonic views.

\section{Theoretical framework: cultural studies and the emergent feminist tradition}

The cultural tradition as it has developed in the fields of both communication and sociology has been aimed specifically at questions of social values, and the role of the mass media in creating, supporting and interacting with social values. I am interested specifically in what the cultural approach has to offer to feminist theory, and to empirical feminist research in communication. It is in this tradition that I locate my own work.

Both the communication and sociology fields have always focused at least some critical attention on issues of social and cultural values, raising questions such as these:

1. Where - in what social texts or artifacts - in what specific teachings - are our social values inscribed?

2. How do we as a society use these texts as tools and means with which to socialize new generations into our cultural value systems?

3. What dissonance occurs among competing values? How is this expressed in our society? Does our society and our culture provide us with any basis upon which to evaluate the merits of these competing points of view? Through what mechanism are these evaluative criteria communicated? (Here I refer specifically to the terms of the Habermas-Gadamer debate.)

4. Finally, the question raised specifically by the Marxist intellectual roots shared by members of the critical school, do our values simply uphold and reinforce an inherently oppressive class and gender social structure? Or again, do they make it possible for members of our society to engage in critical and constructive dialogue concerning these issues, and debating means of their possible resolution? 
Feminist scholars, both sociologists and especially the interdisciplinary group of feminist scholars involved in communication studies, have carried this dialogue and its critique of our cultural consciousness even further. While now fairly well established in the broader communication studies field, primarily by those working in the humanities, feminist communication study and research in the social sciences has been slower to develop. While feminist theory in the communication field has 'taken off', so to speak, and is considered by many to be one of its most exciting and generative areas of theoretical growth, empirical research inspired by these ideas has been somewhat slower to issue forth. Part of the reason for this, of course, may lie in the abstract nature of much of the feminist theorizing which has occurred. The relationship between feminist ideas and feminist research, when these ideas are as abstract as those of the deconstructionist and post-modern feminist theorists and those working with psychoanalytic concepts, is admittedly often perplexing. Another reason for the slower growth of feminist research vis-à-vis theory may be the greater need for research funding in the social sciences, and the lack of a tradition of funding feminist research.

Empirical research informed by a feminist theoretical approach has a great deal to offer to culturally focused communication studies. Many areas of study - women's cultural experience, their reception of cultural messages and products, cultural images of gender, and the potential existence of separate and gendered cultural spheres - have only begun to be examined through feminist research.

The questions occupying this work carry the critical project of cultural communication sociology one step further, bringing the traditional concerns of this group to bear alongside issues arising specifically from the consideration of gender. Questions central to this body of work include the following; some are shared with feminist theory generally, others specific to those interested in studying the issue of culture in particular:

1. Can we call Western society - and most other known societies as well, feminists argue - patriarchal (meaning that gender domination occurs in an intrinsic, characteristic cultural element within the value systems of these societies)? Where again, in what social texts or artifacts, in which teachings - and patriarchal values inscribed? (This question is shared by feminist theorists working in most disciplines.) 
2. How do patriarchal traditions provide the basis for their own critical appropriation by those interested in resisting and subverting patriarchal values? Where can we look for sources, inscriptions, and evidence of this resistance? How can women be both the products of patriarchal society, and its critics as well?

3. Finally, does it make sense to speak of a 'women's culture' existing at some level as a viable subculture of resistance (or accommodation) within complex societies? What other divisions - e.g. social class, race, ethnicity may be relevant to locating and documenting specific women's cultures as they exist and have existed in Western societies?

I see my work as situated within this emergent tradition of empirical feminist research, both regarding the theoretical framework which inspired it, and the methodology I used. I attempt to address resistance (or the lack of it) to elements of mass culture by examining responses to television narrative and characters among women of different classes in the US.

\section{Case study I: I Love Lucy and women's identification with comic characters}

First, I look at a case study comparing working-class and middleclass women's identification with the central character in one of the most-watched entertainment shows on television, the I Love Lucy show. The I Love Lucy show is one of the most successful television shows of all time. Lucy (Lucille Ball). the star of the show, is television's prototypical comic woman. Zany, dingy, wild, but ultimately feisty and strong-willed, the character of Lucy serves as a complex image for women of our time. Predating the era of women's liberation from the post-war era home, Lucy is a traditional wife and mother constantly plotting and scheming to get into her husband's business, the professional entertainment world. The power of her image, however, resonates beyond its surface qualities, and she was one of the most talked-about figures in my interviews.

There are marked differences between what working-class and middle-class women notice about the image of Lucy. While the show was popular with respondents of both classes, it was more popular with the middle-class women to whom I spoke, who gave 
me many more, and more impassioned, comments about it. Most significantly, it was popular in different ways with women of each class. Members of both classes thought Lucy a funny character, but for middle-class women she had more of a positive identity, often as a comedienne in distinction from her comic persona. They also noticed the liberatory or feminist aspects of the Lucy character more often than did working-class informants, identifying her as a strong, independent role model for women, as in the words of this woman:

\footnotetext{
She was this housewife, she was struggling to - I guess to be - she wanted to do something which her husband was doing, and he'd never let her do it . . . but she was also strong in a certain way, because she was the star of the show, she had the power to make everything funny, and to keep the story going - I mean, it was I Love Lucy, it wasn't I love Ricky or Ethel, or anyone else, but she had the strength of her personality. She was more dominant than anybody else, but yet she also struggled in her life. To do something.
}

and of this woman: 'I was always aware that she was the dominant force in the family, in the show'.

As for working-class women, some noticed her strength, but labeled it in less positive ways. They termed her 'manipulative', 'sneaky', a woman dependent on 'feminine wiles' to get what she wanted from men, as in these quotes, for example: 'She was always tricking Ricky - I suppose I used to think that was how women were supposed to be. It never seemed too honest', and 'She has all these feminine wiles, you know, you'd never seem 'em act the fool the way she did.'

Even Lucy's identity as a comic character was perceived somewhat differently by women of each class. Middle-class women admired Ball's skill as a comic actress, seeing the show as a fine piece of comic work, something good for children and the whole family to watch, as in these passages:

I think she's a great comedienne. I don't think the things she got into were plausible, but they were funny. I mean, you took them because it was human, like natural; but it was adorable because it was funny.

Working-class women viewed even Lucy's comic qualities less favorably. They tended to focus their descriptions rather critically on her 'dinginess', or to mention how 'dumb' was the Lucy character, in disparaging ways matched by none of my middleclass informants. 'She was very, you know, dumb, or she did a lot 
of silly things, and stuff like that. But the way she came across on television shows was kind of silly.' Some even complained that Ball's skill as an actress detracted from the reality of her character.

What did I think of Lucy as a character? To me she was always an actress. It's very hard to really believe all the things she was able to accomplish, but she did. But she was always an actress as far as I can see. It was acting . . .

Or, 'I Love Lucy was a very funny show. Everybody enjoyed it. But [and this in a disparaging tone] I couldn't really follow it as real life in any way.' And I wish to stress here that the issue of whether the show was true-to-life was brought up by my informants themselves; it was not an issue which I introduced into the interview situation. It was their own criteria, used to evaluate their likes and dislikes of television programming and characters. These findings led me to suspect that women of different classes may respond differently, specifically to comic female figures. Lucy is almost a feminist figure for middle-class women; whereas these feminist qualities which strike middle-class women so strongly are repudiated by working-class women viewers.

Possible interpretations of these results, and judgements of their significance for the broader issue I investigate, are several. On a methodological note it is possible that working-class women hesitated to tell me that they identified with a character whom they perceived to be so silly. They may have been embarrassed, more so than were middle-class women, to admit to a professional sociologist that they could associate themselves with a character who it seemed to them was not taken entirely seriously. I believe that this is, in part, a reason for some of the responses I received. It was certainly true that working-class women were more easily embarrassed and more hesitant in my presence than were my middle-class informants.

More was at issue on the Lucy questions, however, in my view. Judging from the working-class responses I received overall, my feeling is that while the embarrassment factor may have been operating for some of my respondents, interfering with the very possibility of their admitting an identification with any comic character, it was certainly not the cause of most of the responses I received. I claim this because many informants did not appear embarrassed to discuss their feelings about television shows with me, even feelings about shows they considered to be silly, comic or stupid. This was especially evident in most responses I received 
to questions about I Love Lucy, which provoked much spontaneous enthusiasm among middle-class and working-class informants alike. For the enthusiastic, relaxed working-class women who discussed the Lucy character, factors other than embarrassment or hesitancy seemed to be clearly operating in their lack of identification with her.

For working-class women, I maintain that it is comedy's lack of realism when literally interpreted which accounts for the paucity of their identification with comic television characters. More so than do women of the middle class, working-class women believe that television is, or should be, a mirror of the world, or at least should reflect the world they would like to see. This conviction has a strong impact on the way in which they perceive and interpret television characters and shows, and on the occurrence and manner of their identification with television females. Morley (1986) also found that working-class women dislike slapstick comedy, particularly in a domestic setting. They were disturbed, he claimed, by portrayals of the disruption of domestic order, an order which they work long and hard to maintain. Certainly, the working-class women with whom I spoke seemed quite disturbed by Lucy's challenge to the orderly domestic life which might have prevailed in the absence of her comic shenanigans. Ultimately, I assert, the realistic aura which television assumes for working-class women gives it more power, and power of a different sort, over their lives than it exerts over the lives of middle-class women.

Middle-class women, on the other hand, pick up more directly on the family dynamics, and Lucy's position within them, which are portrayed on the I Love Lucy show. They more freely incorporate her comic qualities into their admiration of the Lucy character for her ongoing struggle to free herself from the confines of an essentially oppressive marriage. ${ }^{1}$ Paradoxically, in this instance television operates almost counter-hegemonically for middle-class women, offering them a feisty female image whose rebellion is directed specifically against her traditional role in the nuclear family.

\section{Case study II: The Cosby Show and women's perceptions of realism}

Moving to my second case study, I investigate more deeply working-class perceptions of realism on television in the context 
of comparing working-class and middle-class women's reactions to the Cosby Show. The Cosby Show features a decidedly uppermiddle-class family. Bill Cosby, who plays the father, is $\mathrm{Dr}$ Heathcliff Huxtable, a medical doctor. His wife Clair (Phylicia Ayers-Allen) is a lawyer. They are black. They live in an extremely nice home and have five children, one of whom they are sending to college. Certainly, the Huxtable family is not representative of black families overall. In fact, with two highly paid professional parents, they are not even representative of white families overall.

Despite this, several working-class women told me that they considered the Cosby's a 'typical' family. ${ }^{2}$ One woman told me of her concern that a family like the Cosby's, rather than the families portrayed on prime-time soaps such as Dallas or Dynasty, should be taken by foreigners to American culture as representative of our culture; she had heard of Dallas' international reputation and was somewhat alarmed by it:

I watch the Bill Cosby Show. It's an average family, working parents, nice house, not wealthy but . . . and that to me is more an American family, you know. Like people from other countries see Dallas and Dynasty, they think that's how we all live. Watch Cosby, I think that's more of a typical American family.

Interviewer: So, Cosby strikes you as a typical individual?

Right, with exaggeration, but that's for television.

Interviewer: And so you say you like to watch some of these shows that you feel portray a typical American family?

Yeah, that I can relate to.

This woman goes on to describe a particular situation, portrayed on the Cosby Show, to which she felt she did relate. The situation involved the Cosby children buying a car. The college-aged daughter in the Cosby family wanted to buy a car, and her father gave her advice regarding which car to buy. This reminded my informant of the time her two teenage boys, wanting a car badly, decided to buy one together. At that time she had advised them that it would never work. The fact that at the time she worked in a factory, and was divorced from her husband, whereas Cosby was a medical doctor and his wife a lawyer, did not seem to interfere with her identification with the situation.

Another working-class woman also likes watching the way in which compromises about money are made in the Huxtable 
household. As an example of the sort of compromises they have to make, she mentions an episode in which Clair wanted to buy an extremely valuable painting from her family, which Cosby allowed her to purchase, even though it was expensive:

Like the episode where she [Clair] wanted the painting which was a lot of money, but it was from her family. He thought it was a lot but it was something she really wanted. You know, so he made allowances for that although I guess she paid for it with her own money, I'm not sure, but that's how you have to have a compromise.

It seems utterly astounding that this very working-class woman, who was first married at fifteen and was divorced by twenty-two, supporting two children with factory work and later with a series of other working-class jobs, identifies so easily with a family whose greatest financial issue is whether or not to purchase an expensive piece of art!

It is even more striking to witness television's hegemonic impact at work in the following case. Another working-class woman had a vicious argument with a friend at work who attempted to argue that the Cosby's were not a representative black family. She herself loves the sort of family relationships portrayed in the show, and resents the suggestion that the Cosby's are not a typical black family.

I like the family relationship [on the Cosby Show]. I had a big discussion with a friend of mine because he claimed that was fantasy and that there is no black family in reality that lives that way, and I got very angry with him.

Interviewer: Why?

Because I don't agree with him. There are black families out there, I knew some personally and I know that they do, yeah, they're just like . . . he was under the impression that black people are poor and uneducated and they have no class [laugh]. It really bothered me that he felt that.

Interviewer: You don't think it's true?

No. I mean a lot of them yes, are in poverty or are lazy, but then I see a lot of Puerto Ricans and a lot of white people living in the same way. It evens out, but I've known a lot of people who were very nice and lived very well and had good jobs and had a nice house ... we had some next to us and they used to take care of us and they were wonderful, very clean people . . . He was saying it was a very unrealistic TV show, that there was no such thing.

Interviewer: And then based on your own experience with this family you think it's not unrealistic?

Yeah, yeah, that's how I feel. 
Given that the percentage of dual professional black families is exceedingly small, I find the vigor with which this woman argues that the Cosby Show is realistic to be quite a tribute to the ability of television images to establish, for some, an alternative vision of the real world. Even if this woman had known one successful, middle-class black family, surely there is enough evidence in the world around her to confirm the high incidence of poverty and unemployment among blacks; in fact, this woman lived in a city area which bordered an extremely poor, largely black section of town. There should have been ample evidence in her experience to support the position alternative to the one she argued.

This woman's attitude attests to the real triumph of that aspect of the hegemonic ideology which states that those who work hard will succeed. It is as though she believes it would be racist to admit that some blacks, or that blacks as a group, have not succeeded, that to believe this would be tantamount to labeling blacks to be lazy and incompetent individuals. Otherwise, how to explain their failure? Her statement indicates the possibility that shows like Cosby could have an extremely conservative effect on perceptions of the true position and needs of minority group members in our society. If shows like Cosby are perceived as an advance for minorities, as capable of correcting racist misconceptions that blacks are poor, they undoubtedly strengthen an individualistic interpretation of poverty's causes, and its remedies. Paradoxically, then, the increasing appearance of minority images on popular television, packaged as they are within the terms of the white middle-class hegemony, may progressively discourage accurate perceptions of minority groups, poverty and prejudice in our society.

Other comments involve the relationship between $\mathrm{Mr}$ and $\mathrm{Mrs}$ Huxtable, and beliefs regarding the representativeness of the Clair Huxtable character vis-à-vis actual professional women overall. Clair Huxtable is depicted as both wife and mother, and as a successful lawyer. The Huxtable family is seen to run quite smoothly, as does Clair's personal and professional life. Conflicts between Clair's roles are minimal, although for real women today conflicts between personal and professional roles prohibit, in most instances, the fulfillment of both to their own satisfaction. Many feminists $^{3}$ have recently commented on the fact that, while popular conceptions of women's right to enter the paid labor force have changed, traditional assumptions about the family form have 
been much slower to alter. As a result, many women find themselves trapped by the demands of both job and family. In neither sphere have demands on women's time been altered to accommodate their dual role.

Clair Huxtable's role on the Cosby Show well illustrates the hegemonic view that families need not change to accommodate working wives and mothers. On the Cosby Show conflicts for the working woman barely exist; they are avoided in part by showing Clair primarily at home, occupied with family rather than workrelated tasks. The relationship between husband and wife is consequently perceived to be free from the pull of Clair's professional obligations.

One working-class woman, for example, mentions what a good relationship the Huxtables have: 'Well, it seems that they have a very good relationship, you know, like he'll help her in the kitchen or to cook or something.' When pressed further as to whether she felt that Clair Huxtable, a successful attorney, wife and mother, was a realistic character, she maintained that in her mind, Clair was realistic:

Interviewer: Do you think she's a typical wife and mother?

Working wife and mother? Probably.

Interviewer: How would you describe Clair?

Concerned, affectionate, caring type person, about her husband and children.

Interviewer: Do you think she's a good attorney?

Oh, I don't know, because there's not much [about Clair's job on the show]. But from her character, my guess would be that she would be a fair attorney.

Interviewer: Why?

Just because of her attitude at home. That she's fair, concerned.

The fact that the show gives next to no information about Clair's work, and pictures Clair exclusively at home rather than at work, does not seem to enter into this woman's judgement that Clair is a 'representative working wife and mother'. According to the show, an attorney like Clair is able to spend a great deal of her time at home, with her family, in postures traditional to the stayat-home wives and mothers of yesteryear (ergo the line, 'he helps her in the kitchen').

I continued the line of questioning started above by asking this woman whether she knew any female attorneys, and if so to 
describe them. As it turned out, she had only met one female attorney in her life, who, it appeared, had been a single woman, quite masculine in appearance, not at all similar to the image of Clair Huxtable. When asked whether Clair or the woman she had known was more representative of female attorneys as a whole, this woman maintained that she took Clair to be more representative, primarily because she's seen other ones on television who had reminded her of Clair:

Interviewer: You know one woman attorney. Did she remind you of Clair?

No. Not even closely. Because she wasn't as feminine as Clair Huxtable.

Interviewer: Who do you think is more typical of women attorneys?

Clair Huxtable.

Interviewer: Why?

Well, because I've seen other ones on television like on the news and other things like that and they are all more feminine than the one that I knew.

This serves as a particularly striking example of an instance in which a working-class woman accepts television images to be more representative of reality than is even her own experience. These findings, though partial and certainly inconclusive, stand as a testament to the potential power television has in our society to define reality for large groups of people whose experience or education may be limited.

Middle-class women seem to focus their comments on different aspects of the Cosby Show and its characters. Instead of the family's economic success, they tend to respond more to the family-oriented aspects of the Cosby Show, perceiving the show as depicting an idealized family but enjoying this portrayal in spite of its lack of realism:

What I feel is unrealistic sometimes is the way they [the Huxtable family] relate to each other. They're wonderful. It's the kind of family life you'd want to live in, you know. They listen to you. That's what I like about it. I like the family unity. And even though they have their differences sometimes, they work them out. And they've dealt with a lot of different subjects in a nice way, it gets the message across.

Another woman mentions the episode of the show on which the entire family celebrated the anniversary of Cosby's parents as being a particular favorite of hers. She enjoyed the image of family unity and happiness which the show presented: 
I enjoyed the show where they celebrated his parents' anniversary . . . and they did the big show at the end, they were all singing. I really enjoyed this one. Because they went to the trouble of doing this for them and it was very creative. His parents were just like my grandmother . . . if I just sent my grandmother a photograph or if I just sent her a letter, my grandmother would be the happiest person in the world. Just the thought that they went to all this trouble, they were really thrilled about it.

Again, middle-class women, while noticing the lack of realism on the show, become involved in the familial relationships which are portrayed and identify with persons and situations despite a perception and judgement of unreality, in line with their greater fundamental similarity to what is, after all, a middle-class family. In their comments, middle-class women more easily move back and forth between their own experience and descriptions of the television characters and situations which directly inspire particular memories and what often adds up to an overall feeling of personal relatedness, which is not quite present in more working-class women's remarks. In general, however, none of the female characters on Cosby inspired the same strong degree of identification which the character of Lucy did for middle-class women. Perhaps too little of the show's conflict and action revolves around them for these characters to command the level of adulation and response which is accorded to Lucy.

\section{Case study III: Working-class women respond to Alice and Who's the Boss}

Finally, I compare working-class women's perceptions of realism in Alice, one of the few shows to feature specifically working-class characters in a working-class setting, with their response to the white middle-class show Who's the Boss. Alice concerns the daily adventures of a widow with a small son who works as a waitress at Mel's Diner. Situations revolve primarily around workplace experiences of Alice (Linda Lavin), her fellow waitresses Flo (Polly Holliday) and Vera (Beth Howland), and their boss Mel (Vic Tayback), who makes a mean bowl of chili ('Mel's Famous Chili'). Flo was later replaced by Belle (Diane Ladd) and then Jolene (Celia Weston) when she left the series in 1980 to star in her own spinoff series, Flo.

Several working-class women with whom I spoke remarked on the unreality, in their view, of the situations, characters, and 
particularly the boss-worker relationships portrayed in Alice. Their perceptions of this unreality seemed to interfere significantly with their pleasure in watching the show:

I used to watch, sometimes, Alice. With Flo. I used to watch it when Flo was on.

Interviewer: What did you think of that show?

Forget it. You know, it was realistic in the sense that, you know, mother single mother raising a child, working in a restaurant. But then she was dating attorneys, doctors - doesn't that seem a little . . . ?

Interviewer: So that brought it out of the realm of being realistic?

Right, because how many women that are working in diners date attorneys? I mean, they date truck drivers or whatever. Flo was more of a realistic character because she did date truck drivers.

Interviewer: Was the character of Alice realistic?

Well, she was realistic in a sense, but a person with that kind of strength would care - well, she was a strong person - wouldn't stay a waitress. You wouldn't stay working in a diner out of loyalty to the other waitresses and the boss. She would start her own restaurant, she would go out and do something different, go to night school.

In this woman's experience, and according to her perception of reality, one can always improve one's situation through hard work and determination. Alice, which depicts a strong woman working in a dead-end job and apparently making little attempt to improve her situation, contradicts this woman's conception of the way in which a real woman, with Alice's qualities, would behave in this situation. The show certainly contradicts her apparent judgement of how a real woman should behave in this situation. Perhaps Alice is disturbing in that the show confronts her with images which contradicts what she would like to believe is true: that no strong, intelligent woman need remain a waitress for very long.

It is interesting that the woman quoted above goes on to comment that Flo, being more of a comic character, was to her a less unrealistic image, implying that she is not offended when a comic figure on television acts in a manner she finds unrealistic: 'I would say, like, Flo was more of a comic type of character. That was real, but a strong person wouldn't [stay in that situation]'.

The distinction made here between this viewer's expectations of a character whom she perceives to be 'strong' or dramatic (Alice) as opposed to a character whom she perceives to be comic (Flo) are interesting in light of my discussion of working-class women's 
response to television's comic women in the discussion of I Love Lucy, above. Remember too that this woman specifically mentions her affection for, and enjoyment of, the character Flo, that she stopped watching the show when Flo left it. As in the case of judgements working-class women made of the Lucy character in the I Love Lucy show, it seems to be difficult for this woman to express truly positive sentiments about a comic character (Was Flo strong also? If she was, why would she remain working in Mel's Diner? Was Alice the only strong figure in the diner? Why was Flo a more realistic character than Alice?).

Another woman comments on the work situation as portrayed in Alice:

Interviewer: Do you think that show is very true to life?

As far as the working place, no. Because I've done that type of work and for one thing when I say I like the way they handle [Mel's] chauvinistic attitudes, he's still their boss and they're working for him and they owe him a certain amount of respect. That's my opinion.

Interviewer: And so you think on the show they don't really show him that respect that they would actually owe him in real life?

No. Because even though like they say about his chili, you know, I know it's just to get laughs, but in real life even if I worked for this man and I hated his chili, I wouldn't [tell him]. Yeah, I might, if they said do you have any suggestions I might suggest not trying the chili, I wouldn't be dishonest, with my customers, but I still wouldn't belittle the man.

The light-hearted attitude toward work presented on Alice seems to have offended this woman, or at least to have touched a base which is close to home. She holds some very strong opinions about the sort of interaction between a boss and his or her workers which is correct or right. The comic treatment this set of relationships receives in the situations and characters shown on Alice subverts some of the, to her mind, sacred rules which ought to govern here, and she is not amused. Again, this woman has some difficulty in allowing comedy to wreak havoc with reality, and in this situation she is well grounded experientially in the reality upon which this comedy is based.

It is interesting, however, that this woman began her discussion of Alice by mentioning the fact that she enjoyed watching the three waitresses work together to manipulate the chauvinistic Mel:

I liked the way the three waitresses manipulate Mel, because he is so 
chauvinistic. And they have their own ways of getting around him. That's mostly why I like that show. Or the character of Alice.

So in fact, despite her disapproval of it, the manipulative behavior the working women display toward their boss does seem to touch this woman in an important way. It is, she claims, the main reason she derives pleasure from the show. She perhaps has an unconscious fantasy of rebellion against the bosses to whom she has shown so much respect throughout her life, and it is to this that the show speaks. Her conscious judgements of the show do not reflect the power of this fantasy, however. Consciously, she finds the work situations depicted on Alice to be grossly unrealistic, and this seems to interfere somewhat with her overall enjoyment of the show, as I demonstrate further in the discussion below.

The woman quoted above lived through familial as well as work experiences which also bear some similarity to the character Alice's situation. Divorced at an early age, she brought up two sons single-handedly, with little help from her husband or family. She struggled through her life working at a series of relatively lowpaying, unskilled jobs. Yet when asked whether Alice's situation reminds her of her own, she denies it:

Interviewer: Do you think you like shows, a show like Alice, because it reminds you of your situation, of what it was?

No, no. I think I probably . . . like I say, I enjoy the three of them together. If you take Alice alone, I don't know that I would enjoy her as much. I like the interaction between the three. You know, I think they complement each other. I just view it as entertainment, because like I say there's not much about her son and their relationship or about how she struggles financially.

Here she seems to indicate that it is easier for her to identify with the work group pictures on this show, than with the main character's individual family situation which, again, she judges as unrealistic in its portrayal.

However, what throws some doubt on this hypothesis is her response to the next set of questions which I posed to her, which involved comparing her reactions to Alice and to another popular show which she enjoys, Who's the Boss. Who's the Boss stars Judith Light playing Angela Bower, a high-powered advertising executive who hires Tony (Tony Danza) to run her household and help in raising her child. Of course, like Alice, Angela is a single mother. Yet unlike Alice she is an upper-middle-class highly paid 
professional. In one episode, Angela is fired from her job due to mishaps at home and, failing to locate another position easily, decides to go into business as an advertising consultant for herself. The whole family helps out, her mother acting as her secretary, Tony redecorating, until she gets started.

My informant, though working-class herself, preferred Who's the Boss to Alice because, to her, the former was more realistic. She particularly enjoyed the way in which family finances were portrayed on Who's the Boss:

Interviewer: What about comparing a show like Alice to a show like Who's the Boss? If you had a choice of watching one of those two shows, which one would it be?

Who's the Boss. Because it's more realistic a lot of times. Like with her starting a new business, you know, they all pitched in and helped to get this place ready. Now that's something people would do and they did without a lot of things to help her get started and when she was finally, ah, in the black there was a little celebration. You know, it was like a group effort. It's like they're saying you have to sacrifice certain things to get ahead, to gain, and it's a gamble.

Referring to another episode of the show on which Angela had to put off putting in a pool in her backyard until the business got off the ground, this woman goes on to praise the greater realism of Who's the Boss over images of the wealthy on the night-time soap opera Dallas:

There was a thing [on Who's the Boss] like one time where it's either a pool or this. They don't have that much money that they can do what they want to do when they want to do it like Dallas.

Interviewer: And so you feel that is why you would rather watch a show like that than Dallas?

Because it's more realistic. They're not wealthy people, but they're, they're like working-class people. She was paid very well where she worked, but now she's on her own and she dresses very nicely, but it's still a homey atmosphere. And like the place isn't furnished elegantly, it's furnished very nice, it's a nice house.

When compared to the lavish wealth of Dallas, almost any middleclass family would look more realistic. But to judge a successful advertising executive to be working class? At the same time that one judges this allegedly 'working-class' show to be more realistic than Alice? There is a general skewing of imagery and judgements in these passages which merits further discussion. Perhaps television's role as wish-fulfillment goes only so far. Possibly it is too 
disturbing for working-class women to watch, and to accept as real, the lavish wealth of a show like Dallas. Middle-class prosperity as depicted on Who's the Boss and on so many other shows, however, may provide a more acceptably 'realistic' set of wishes for working-class viewers, who would likely be thrilled to achieve the level of affluence they chronicle.

\section{What is reality? Escapism for working-class women}

One problem working-class women may experience in attempting to identify with the working-class images which do appear on television may involve the fact that many working-class images on television are comic images. Working-class women do not readily identify with comic images,${ }^{4}$ in part because they perceive them to be unrealistic. For example, several told me that they enjoyed the show Laverne and Shirley, which pictures the adventures of two young working-class women, but they phrased their comments in terms of noticing and praising the show's humor rather than in their ability to identify with, or relate to, the main characters. Another woman remembers herself laughing hysterically when watching The Honeymooners, a show about a working-class couple. This woman had been a battered wife for many years, but had never related her experiences to the many arguments or threats of violence depicted between husband and wife in that show. Again, here it may be that comedy interfered with the identification process. Or that working-class women avoid identifying with images which somewhat too realistically evoke real-life pain.

One working-class woman stated her desires from television for me quite clearly. She had just described in great detail a soap opera to which she was addicted, criticizing many of the characters and situations for their lack of realism. However, when asked if she would prefer more realistic characters or situations on television - poor women, for example, or women who worked for a living - she denied it. While she liked television to be fairly realistic, she did not wish to see too problematic a reality:

It takes the fantasy away. When it's something that's totally unreal you expect it to stay that way. Who wants to see welfare mothers or working women who go home to a bunch of screaming kids? You don't want to see that on TV. 
She goes on to illustrate her point in the context of describing the show Kate and Allie, and her reaction to it. Kate (Susan Saint James) and Allie (Jane Curtin) were two divorced women, old friends, who decided to move in together with their children to form a household following their divorces. Allie, the old-fashioned one, kept house for Kate, the glamorous career woman. The show is interesting in that it plays the roles of the two women traditional and modern - off each other. Plots revolve around various problems one or both of the two women experience in the course of their lives. It has been widely praised among television critics for its realism, and for the sensitivity with which the relationship between the two women in particular is portrayed.

My informant describes the show in these unflattering terms:

Well, it was these two women with their problems. I don't know what it was like 'cause I just didn't like it too much. I just watched it because it was supposed to be so good.

She ends up, not surprisingly, criticizing the show for its lack of (of all things) realism:

Well, I guess the repartee, and the way they discuss and handle them [their problems] seems still unreal. I mean, life is really slow. It's not always an incident or entertaining, funny issue. Real life is just - can be quite a drudge. You know, the same old problems. You have to make your challenges.

On the one hand, we are told that the drudge of real life is an unfitting subject for television - 'it takes the fantasy away'. On the other, Kate and Allie, a show about problems, is unreal, failing to capture the dull drudgery of real life. This woman, at least, seems caught between the desire for more realistic television and a desire for fantasy or escape.

Another woman expresses a similar sentiment, arguing that television shows depicting children on drugs and in other sorts of trouble hit too close to home - are a little too realistic - and that people she knows certainly don't want to see this, to be reminded of the potential problems they or their children might face. She too is a working-class woman who maintained throughout her interview a strong preference for realistic television,

They think that the children want to see children who are screwed up - because that's what they are - and children who are promiscuous, children who are alcoholics, children who are on drugs. Maybe the children want to see it; I don't 
think that the old people want to see it. First of all they are happy that their children weren't on it.

She goes on to describe her particular fears regarding her children's exposure to the drug scene in college. As demonstrated above in other contexts, when television images hit too closely to home, or touch topics actually troubling a woman at a given moment in time, she is likely to judge these images to be unrealistic. The situation in which television presents her with idealized images that have less actual relationship to her real life, but more easily conform to her fantasies and dreams, is more likely to meet with both her general approval and, from workingclass women, specific praise for its 'realism'.

\section{Conclusion}

In this work I have used an open-ended, unstructured interviewing technique in order to investigate differences between the way in which working-class and middle-class women understand, identify with, and use television narrative and characters. Results yielded interesting differences between the classes of women I have studied. Working-class women and middle-class women have different expectations of television. The former criticize television for its lack of realism, and evaluate shows at least in part on their success in mimicking real-life people and events. The more 'realistic' working-class women find a show and its characters to be, the more likely it is that they have enjoyed it sufficiently to watch it fairly regularly. Their evaluations of realism, however, seem to reflect their wishes about reality - reality, particularly material reality, as they would like it to be - rather than some more objective assessment of television's truly realistic character. There is a tension between the working-class search for realism in television, and working-class women's desire to use television for escapist purposes, which is also pervasive.

Overall, I found that the less solidly, soberly middle class or upper class are female characters on television, the less likely are working-class women to identify with them. In fact, the few television women showing any signs of dissatisfaction with their societal status, Lucy for example, or the few solidly working-class television women characters, are often loudly denounced by 
working-class informants for their lack of realism, even though, as in the Lucy example discussed above, these same characters can serve as feminist, critical figures for middle-class viewers. Middleclass characters, however, whom the television critic might judge to be just as unrealistic as are television's working-class characters, were much more often accepted as realistic by working-class informants. One might say that working-class women define realism, in effect, to mean what they wish real life to be, rather than what they experience their own lives to be.

Because the vast majority of television characters are middle class or upper class, my study indicates that television seems to support what I call an 'hegemony of middle-class realism' for working-class women, and as such may operate in part to blind working-class women to the realities of their own situation in society. When their experience is addressed directly, as the few working-class images on television begin to do, working-class women are moved to articulate their difference from, and reality apart from, these images. However, because this happens so rarely, American television entertainment in its present form encourages the denial of this experience, or its submergence under an ultimately unrealistic belief in television's idyllic picture of middle-class life.

For middle-class women, however, already living the middleclass material life depicted in the vast majority of television products, television's hegemonic importance rests more in the form of the family, and of women's role within it, which it portrays in the context of middle-class life. With some exceptions, television portrays women, even professional women, who put family duties and responsibilities before those of their jobs or careers, and who seem unconflicted about this choice. However, when television women do express dissatisfaction with their role in the family, as is striking in the case of the I Love Lucy show, television can operate counter-hegemonically for female middleclass viewers. Many label Lucy to be a strong and determined woman fighting for autonomy in an oppressive marriage. Like Morley (1986), who found that working-class women dislike comic disruptions of domestic order, I too found that working-class women were prevented by the I Love Lucy show's comic context from discerning and identifying with the liberated woman which middle-class women found so inspiring.

In sum, there are important differences regarding the way in 
which television is perceived, experienced, and used between class-differentiated groups of women in the contemporary United States. These differences may relate to broader class differences which may exist. Questions concerning the possibility that social classes and genders in our society occupy different cultures, speak different languages, and are oriented to the world in fundamentally different ways, have all been raised in other contexts in the social scientific study of classes and cultures in contemporary societies. ${ }^{5}$ The possibility that differences between groups of women can be traced to class-specific characteristics poses a fundamental challenge to feminists who have argued that women themselves in our society constitute a specific culture (Hacker, 1951) or class (Hartmann and Bridges, 1979). Considerations of class in particular (along with race and ethnicity) have raised serious questions regarding some of the foundations of much of the feminist theory concerning women's status as a social group, ideas which have been central to both academic and political feminists movements in our time.

This study raises the possibility that the categories of class and gender are crucially important for the study of media audiences. In my work I argue that television is a complex medium which bolsters the patriarchal hegemony in class-specific and genderspecific ways. Television entertainment can be seen to foster a two-edged hegemony of beliefs and practices, which serve our society's dominant class and gender interests. Much more work on audience reception of television remains to be done before the full contribution of these ideas, both to media theory and to broader questions of feminist theory, can be assessed. I hope that this preliminary work will be useful for future researchers and theorists in both of these fields.

\section{Notes}

This paper was first presented at the 1988 International Television Studies Conference. The data presented are culled from a larger study involving interviews with approximately twenty working-class and twenty middle-class women. See Press, Women Watching Television (Philadelphia: University of Pennsylvania Press, forthcoming), for a fuller explanation of the methodology of that study.

1. See Press (1987), especially Chapter Two, for a fuller discussion and analysis of the plotlines characteristic of the I Love Lucy show. As I demonstrate there, 
much of the show is characterized by Lucy's struggle against her dominating husband.

2. The women quoted in this section are white. It would of course be interesting and important to garner the responses of black women to shows portraying them, but such an investigation was beyond the scope of my study. I regretfully leave this task to future investigators.

3. See, for example, Hewlett (1986), Friedan (1981), and Eisenstein (1981) and (1984).

4. See my discussion of the difficulty working-class women have in identifying with comic images in my dissertation (Press, 1987), particularly in Chapter Three which is entitled 'Women's Identification with Television Narrative and Characters.'

5. On questions of class culture, see Hyman (1953) and Lewis (1959 and 1966). Regarding differences between working-class and middle-class languages, see Bernstein (1958 and 1966). Schatzman and Strauss (1955), in a dated yet relevant piece, raise the issue of class-specific orientations to thought.

\section{References}

Bernstein, Basil (1958) 'Some Sociological Determinants of Perception', British Journal of Sociology IX(2): 159-74.

Bernstein, Basil (1966) 'Elaborated and Restricted Codes: Their Social Origins and Some Consequences' in A.G. Smith (ed.) Common Culture. New York: Holt, Rinehart and Winston. (First published 1964.)

Eisenstein, Zillah (1981) The Radical Future of Liberal Feminism. New York: Longman.

Eisenstein, Zillah (1984) Feminism and Sexual Inequality: Crisis in Liberal America. New York: Monthly Review.

Friedan, Betty (1981) The Second Stage. New York: Summit Books.

Hacker, Helen (1951) 'Women as a Minority Group', Social Forces 30:60-9.

Hartmann, Heidi and Amy Bridges (1979) 'The Unhappy Marriage of Marxism and Feminism: towards a more progressive union', Capital and Class, Summer.

Hewlett, Sylvia Ann (1986) A Lesser Life: The Myth of Women's Liberation in America. New York: William Morrow.

Hyman, Herbert (1953) 'The Value Systems of Different Classes', in R. Bendix and S.M. Lipset (eds) Class, Status and Power, pp. 426-42. Glencoe, Illinois: Free Press.

Lewis, Oscar (1959) Five Families: Mexican Case Studies in the Culture of Poverty. New York: Basic Books.

Lewis, Oscar (1966) La Vida: A Puerto Rican Family in the Culture of PovertySan Juan and New York. New York: Random House.

Morley, David (1986) Family Television. London: Comedia.

Press, Andrea (1987) 'Deconstructing the Audience: Class Differences in Women's Identification with Television Narrative and Characters'. Ph.D. thesis, Sociology Department, University of California at Berkeley.

Schatzman, Leonard and Anselm Strauss (1955) 'Social Class and Modes of Communication', American Journal of Sociology LX(4): 329-38. 